\title{
PENGARUH KUALITAS PELAYANAN DAN KEPERCAYAAN TERHADAP KEPUASAN NASABAH
}

\author{
(Studi Pada Bank Mandiri Cabang Alam Sutera Tangerang)
}

\author{
Kirana Apsari Ayuningtyas ${ }^{1}$, Salim Siregar ${ }^{2}$ \\ apsarikirana0@gmail.com ${ }^{1}$ \\ salim@fe.unsika.ac.id ${ }^{2}$ \\ Fakultas Ekonomi dan Bisnis, Universitas Singaperbangsa Karawang
}

\begin{abstract}
ABSTRAK
Kualitas Pelayanan menjadi gambaran dan acuan bagi para konsumen dalam membeli atau menggunakan sebuah produk atau jasa, tingkatan keunggulan (excellence) yang diharapkan dan pengendalian atas keunggulan tersebut dan merupakan alat sebagai ukuran seberapa bagus tingkatan layanan yang diberikan mampu sesuai dengan ekspektasi pelanggan. Kepercayaan merupakan keyakinan bahwa seseorang akan menemukan apa yang diinginkan pada mitra pertukaran. Kepuasan nasabah merupakan suatu konsep yang telah lama dikenal dalam ilmu pemasaran. Di saat persaingan semakin ketat, produsen berusaha memenuhi kebutuhan dan keinginan konsumen dengan menawarkan berbagai jenis produknya, dampaknya konsumen memiliki banyak pilihan, kekuatan tawar-menawar konsumen semakin besar, yang mendorong setiap perusahaan harus menempatkan orientasinya pada kepuasan pelanggan sebagai tujuan utamanya. Tujuan penelitian ini mencari pengaruh secara parsial maupun simultan dari variabel Kualitas Pelayanan dan Kepercayaan Terhadap Kepuasan Nasabah. Penelitian ini merupakan penelitian kuantitatif dengan metode penelitian deskriptif dan verifikatif. Populasi diambil untuk penelitian ini sebanyak data diambil berdasarkan hasil observasi awal di Bank Mandiri Cabang Alam Sutera Tanggerang. Sampel dalam penelitian ini berjumlah 322 responden menggunakan teknik sampling purposive sampling. Hasil penelitian menunjukan bahwa Kualitas Pelayanan dan Kepercayaan berpengaruh secara parsial maupun simultan terhadap Kepuasan Nasabah Bank Mandiri Cabang Alam Sutera Tanggerang. Hasil penelitian menunjukan bahwa Kualitas Pelayanan dan Kepercayaan mempunyai hubungan yang sangat kuat ditunjukan dengan nilai korelasi sebesar 0,968.
\end{abstract}

Kata Kunci: Kualitas pelayanan, Kepercayaan, dan Kepuasan nasabah.

\section{ABSTRACT}

Service Quality is a description and reference for consumers in buying or using a product or service, the level of excellence expected and control over these advantages and is a tool as a measure of how well the level of service provided is able to match customer expectations. Trust is the belief that someone will find what they want in an exchange partner. Customer satisfaction is a concept that has long been recognized in marketing science. At a time when competition is getting tighter, producers are trying to meet the needs and desires of consumers by offering various types of products, the impact is that consumers have many choices, the bargaining power of consumers is getting bigger, which encourages each company to place its orientation on customer satisfaction as its main goal. looking for influence partially or simultaneously from the variables of Service Quality and Trust Toward Customer Satisfaction.This research is a quantitative research 
with descriptive and verivative research methods. The population was taken for this research as much as the data was taken based on the results of preliminary observations at Bank Mandiri Alam Sutera Tanggerang Branch. The sample in this study amounted to 322 respondents using purposive sampling technique. The results showed that the quality of service and trust partially and simultaneously affect customer satisfaction at Bank Mandiri Alam Sutera Tanggerang branch.The results showed that Service Quality and Trust had a very strong relationship as indicated by the correlation value of 0.968.

Keywords: Service quality,Trust, and Customer Satisfaction.

\section{PENDAHULUAN}

Menurut UU No. 10 Tahun 1998 Bank konvesional adalah bank yang melaksanakan kegiatan usaha secara konvensional yang dalam kegiatannya memberikan jasa dalam lalu lintas pembayaran yang bertujuan untuk membantu melaksanakan pembangunan nasional untuk mencapai pemerataan, peningkatan kesejahteraan masyarakat dan pertumbuhan ekonomi yang pada dasarnya kegiatan ekonomi dan pembangunan di Indonesia sangat erat kaitannya dengan perbankan. Berdasarkan kepemilikannya, bank di klasifikasi menjadi bank pemerintah, bank campuran, bank swasta nasional, dan bank swasta asing. Pada saat ini, semua orang membutuhkan layanan perbankan. Selain untuk menabung dan melakukan pinjaman, bank juga dijadikan sebagai sarana untuk melakukan pembayaran-pembayaran tagihan-tagihan dan segala bentuk transaksi lainnya yang dapat dilakukan melalui layanan yang ditawarkan oleh perbankan. Dalam hal ini, PT. Bank Mandiri Tbk Cabang Tangerang Alam Sutera yang merupakan Bank Konvensional (BUMN) yang bergerak pada bidang jasa keuangan perbankan, dan dituntut untuk dapat menciptakan bisnis dengan memberikan pelayanan semaksimal mungkin untuk dapat meningkatkan kepuasan nasabah mereka. PT Bank Mandiri Tbk (BMRI) mencatat sekitar 10 tahun yang lalu, 17\% transaksi perbankan masih berasal dari kantor cabang. Saat ini, angka tersebut turun, karena kondisi transaksi sudah berubah ke ranah digital. "sekarang 4-5\% saja. Semua pindah ke channel digital, misalnya Mobile Banking, ATM, EDC, internet banking,"

Tabel 1.Jumlah Asset Bank Mandiri tahun 2016-2019

\begin{tabular}{ccc}
\hline No & Tahun & Asset (Dalam juta rupiah) \\
\hline 1 & 2016 & $918,181,510$ \\
2 & 2017 & $978,377,431$ \\
3 & 2018 & $1,037,077,806$ \\
4 & 2019 & $1,097,658,366$ \\
\hline \multicolumn{2}{c}{ Total } & $4,031,295,113$
\end{tabular}

Sumber: kinerjabank.com 
Dapat dilihat pada Tabel 1. bahwa asset yang dimiliki PT. Bank Mandiri (Persero) selama periode tahun 2016-2019 mengalami peningkatan tanpa mengalami penurunan sama sekali.

Tabel 2.Tabel Peringkat Bank Umum tahun 2019

\begin{tabular}{|c|c|c|}
\hline Peringkat & Bank & Total Asset \\
\hline 1 & PT BANK RAKYAT Indonesia (PERSERO), TBK (BRI) & $1,238,657,773$ \\
\hline 2 & PT BANK MANDIRI (PERSERO), TBK (MANDIRI) & $1,097,658,366$ \\
\hline 3 & PT BANK CENTRAL ASIA, TBK (BCA) & $875,677,023$ \\
\hline 4 & PT BANK NEGARA INDONESIA, TBK (BNI) & $756,755,688$ \\
\hline 5 & PT BANK TABUNGAN NEGARA, TBK (BTN) & $316,211,345$ \\
\hline 6 & PT BANK CIMB NIAGA, TBK (CIMB NIAGA) & $260,881,792$ \\
\hline 7 & PT PAN INDONESIA BANK, TBK (PANIN) & $192,939,358$ \\
\hline 8 & PT BANK OCBC NISP, TBK (OCBC NISP) & $175,449,266$ \\
\hline 9 & $\begin{array}{l}\text { PT. BANK TABUNGAN PENSIUNAN NASIONAL, TBK } \\
\text { (BTPN) }\end{array}$ & $168,918,673$ \\
\hline 10 & PT BANK DANAMON INDONESIA, TBK (DANAMON) & $168,247,629$ \\
\hline 11 & PT BANK MAYBANK INDONESIA, TBK (MAYBANK) & $163,721,487$ \\
\hline 12 & PT BANK PERMATA, TBK (PERMATA) & $154,908,997$ \\
\hline 13 & $\begin{array}{l}\text { PT BANK BPD JAWA BARAT DAN BANTEN, TBK } \\
(\text { BJB) }\end{array}$ & $117,346,330$ \\
\hline 14 & $\begin{array}{l}\text { PT BANK HSBC INDONESIA, TBK (HSBC } \\
\text { INDONESIA) }\end{array}$ & $111,706,071$ \\
\hline 15 & PT BANK DBS INDONESIA, TBK (DBS) & $93,948,133$ \\
\hline 16 & $\begin{array}{l}\text { PT BANK MAYAPADA INTERNASIONAL, TBK } \\
\text { (MAYAPADA) }\end{array}$ & $92,219,734$ \\
\hline 17 & PT BANK BUKOPIN, TBK (BUKOPIN) & $91,221,902$ \\
\hline 18 & PT BANK MEGA, TBK (MEGA) & $87,808,884$ \\
\hline 19 & PT BANK BPD JAWA TENGAH (BPD JATENG) & $76,239,427$ \\
\hline 20 & PT BANK MIZUHO INDONESIA (MIZUHO) & $67,868,745$ \\
\hline 21 & PT BANK BPD DKI (BPD DKI) & $50,222,794$ \\
\hline 22 & PT. BANK KEB HANA INDONESIA (HANA) & $47,732,585$ \\
\hline 23 & PT BANK COMMONWEALTH (COMMONWEALTH) & $22,203,536$ \\
\hline
\end{tabular}




\begin{tabular}{clc}
\hline Peringkat & \multicolumn{1}{c}{ Bank } & Total Asset \\
\hline 24 & PT BANK CAPITAL INDONESIA, TBK (CAPITAL & $19,192,375$ \\
& INDONESIA) & \\
25 & PT BANK CHINA CONSTRUCTION BANK INDONESIA & $18,098,687$ \\
& TBK & \\
26 & PT BANK BUMI ARTA, TBK (BUMI ARTA) & $7,148,922$ \\
\hline
\end{tabular}

Sumber: kinerjabank.com

Pada Tabel 2. diketahui bahwa PT. Bank Mandiri (PERSERO) berada pada urutan kedua dari 26 bank lainnya pada tahun 2019 yang memiliki asset sebesar 1,097,658,336.

Tabel 3.Data jumlah PT. Bank Mandiri Cabang Tangerang Alam Sutera tahun 2019

\begin{tabular}{ccc}
\hline No. & Bulan & Jumlah Nasabah \\
\hline 1. & Januari & 1.778 \\
2. & Febuari & 1.986 \\
3. & Maret & 2.233 \\
4. & April & 1.776 \\
5. & Mei & 1.809 \\
6. & Juni & 1.238 \\
7. & Juli & 1.711 \\
8. & Agustus & 1.630 \\
9. & September & 1.571 \\
10. & Oktober & 1.235 \\
11. & November & 1.263 \\
12. & Desember & 1.329 \\
\hline
\end{tabular}

Sumber: Bank Mandiri Cabang Tangerang Alam Sutera tahun 2019

Pada tabel 3. menunjukkan Data jumlah PT Bank Mandiri Cabang Tangerang Alam Sutera pada tahun 2019.Pada awal tahun 2019 hingga akhir tahun 2019 jumlah nasabah mengalami fluktuasi. Pada bulan Februari dan Maret, menunjukkan terjadinya kenaikan jumlah nasabah di PT Bank Mandiri Cabang Tangerang Alam Sutera. Dan pada pada bulan April sebesar 457 orang mengalami penurunan jumlah nasabah di PT. Bank Mandiri Cabang Tangerang Alam Sutera. Serta mengalami ketidakstabilan pada bulan Mei hingga Juli, dan terjadi penurunan secara terus-menerus hingga bulan November, dan pada bulan desember jumlah nasabah PT Bank Mandiri Cabang Tangerang Alam Sutera mengalami peningkatan. Dari data diatas yang menunjukan adanya fluktuasi data nasabah, dapat menunjukan seberapa tinggi tingkat kepuasan yang dirasa nasabah dalam memperoleh pelayanan dan kepercayaan dari Bank Mandiri. 


\section{RUMUSAN MASALAH}

Adapun rumusan masalah dalam penelitian ini adalah :

1. Seberapa besar pengaruh parsial kualitas pelayanan terhadap kepuasan nasabah PT Bank Mandiri Tbk Cabang Tangerang Alam Sutera?

2. Seberapa besar pengaruh parsial kepercayaan terhadap kepuasan nasabah PT Bank Mandiri Tbk Cabang Tangerang Alam Sutera?

3. Seberapa besar pengaruh simultan kualitas pelayanan dan kepercayaan terhadap kepuasan nasabah pada PT Bank Mandiri Tbk Cabang Tangerang Alam Sutera?

\section{TUJUAN PENELITIAN}

Tujuan penelitian ini adalah sebagai berikut :

1. Untuk mengetahui, menganalisis dan menjelaskan pengaruh parsial antara kualitas pelayanan terhadap kepuasan nasabah pada PT Bank Mandiri Tbk Cabang Alam Sutera Serpong.

2. Untuk mengetahui, menganalisis dan menjelaskan pengaruh parsial antara kepercayaan terhadap kepuasan nasabah pada PT Bank Mandiri Tbk Cabang Tangerang Alam Sutera.

3. Untuk mengetahui, menganalisis dan menjelaskan pengaruh simultan antara kualitas pelayanan dan kepercayaan terhadap kepuasan nasabah pada PT Bank Mandiri Tbk Cabang Tangerang Alam Sutera.

\section{LANDASAN TEORI DAN PENGEMBANGAN HIPOTESIS}

\section{Pengaruh Kualitas Pelayanan terhadap Kepuasan Pelanggan pada Nasabah Bank Mandiri Cabang Alam Sutera Serpong.}

Fandy Tjiptono (2012: 125) menyatakan bahwa dengan memperhatikan kualitas pelayanan kepada konsumen akan meningkatkan indeks kepuasan kualitas konsumen yang diukur dalam ukuran apapun dengan dimensi kualitas pelayanan yaitu tangible, emphaty, reliability, responsiveness dan assurance. Dan Penelitian terdahulu yang dilakukan oleh Lee Hyung Seok. 2013,Madona, F. (2017), Mustaqim, M. (2016), Dewi, A., dan Sri Padmantyo, M. B. A. (2017), dan Putri, N. J. (2016) yang berpendapat bahwa kualitas pelayanan berpengaruh positif dan signifikan terhadap kepuasan pelanggan. Sehingga diperoleh hipotesis dalam penelitian ini adalah :

H1 : Terdapat Pengaruh antara Kualitas Pelayanan terhadap Kepuasan Pelanggan pada Nasabah Bank Mandiri Cabang Alam Sutera Serpong.

\section{Pengaruh Kepercayaan terhadap Kepuasan Pelanggan pada Nasabah Bank Mandiri Cabang Alam Sutera Serpong.}

Berdasarkan hasil penelitian yang dilakukan oleh Erviana, O. (2013). diperoleh hasil bahwa kepercayaan berpengaruh terhadap kepuasan pelanggan secara signifikan. berdasarkan hasil analisis deskriptif variabel kepercayaan, dimensi dari kepercayaan yang 
paling berpengaruh terhadap kepuasan pelanggan adalah dimensi kebaikan hati, hal ini dikarenakan perusahaan tetap memberikan pelayanan yang baik terhadap konsumen tanpa membedakan status sosial. Penelitian ini juga didukung dengan hasil penelitian Guspul, A. (2014) dan Akfian Yuda Adhi et.al (2013), yaitu kepercayaan berpengaruh signifikan terhadap kepuasan. Sehingga diperoleh hipotesis dalam penelitian ini adalah :

H2 : Terdapat Pengaruh antara Kepercayaan terhadap Kepuasan Pelanggan pada Nasabah Bank Mandiri Cabang Alam Sutera Serpong.

\section{PengaruhKualitas Pelayanan dan Kepercayaan terhadap Kepuasan Pelanggan pada Nasabah Bank Mandiri Cabang Alam Sutera Serpong.}

Hasil penelitian yang dilakukan oleh Okky Erviana (2013) diperoleh hasil bahwa kualitas pelayanan dan kepercayaan berpengaruh signifikan terhadap kepuasan pelanggan, dengan melihat besarnya pengaruh kedua variabel independen terhadap variabel dependen, dan bisa dikatakan terciptanya kepuasan pelanggan adalah karena layanan yang diberikan dapat memberikan kepuasan kepada pelanggan. Penelitian ini didukung dengan hasil penelitian Guspul, A. (2014) dan Akfian Yuda Adhi, et.al (2012), menyatakan bahwa kualitas pelayanan dan kepercayaan berpengaruh positif dan signifikan terhadap kepuasan pelanggan. Sehingga diperoleh hipotesis dalam penelitian ini adalah :

H3 : Terdapat Pengaruh antara Kualitas Pelayanan dan Kepercayaan terhadap Kepuasan Pelanggan pada Nasabah Bank Mandiri Cabang Alam Sutera Serpong.

\section{METODE PENELITIAN}

\section{Populasi}

Menurut Sugiyono (2011:80), bahwa populasi adalah wilayah generalisasi yang terdiri atas objek atau subjek yang mempunyai kualitas dan karakteristik tertentu yang ditetapkan oleh peneliti untuk dipelajari kemudian ditarik kesimpulannya. Populasi dari penelitian ini adalah rata-rata 1630 nasabah per bulan pada Bank Mandiri Cabang Alam Sutera Tangerang dan nasabah pertahun berjumlah 19.559 nasabah periode 2019 .

\section{Sampel}

Sampel adalah bagian dari jumlah dan karakteristik yang dimiliki oleh populasi tersebut. Bila populasi besar dan peneliti tidak mungkin mempelajari semua yang ada pada populasi, misalnya karena keterbatasan dana, tenaga, dan waktu, maka peneliti dapat menggunakan sampel yang diambil dari populasi itu. (Sugiyono,2012:81). Berdasarkan populasi sebanyak 1630 orang dan berdasarkan rumus slovin dengan menggunakan taraf kesalahan 5\% didapatkan sampel sebanyak 322 orang.

\section{Teknik Sampling}

Teknik pengambilan sampel yang digunakan adalah non probability sampling. Metode pemilihan sampel yang digunakan adalah sampling insidental merupakan teknik penentuan sampel berdasarkan kebetulan, yaitu siapa saja yang secara kebetulan/insidental 
bertemu dengan peneliti dapat digunakan sebagai sampel, bila dipandang orang yang kebetulan ditemui itu cocok sebagai sumber data. (Sugiyono, 2012:85).

\section{Jenis Data}

\section{Data Primer}

Data primer adalah data yang diperoleh secara langsung dengan melakukan observasi, yaitu penulis melakukan penyebaran kuesioner kepada pihak yang dianggap dapat memberikan informasi mengenai data-data yang dibutuhkan sebagai bahan pelengkap dalam penyusunan skripsi. Dalam hal ini data yang diperoleh yaitu data primer yang menyangkut kualitas pelayanan, kepercayaan dan kepuasan pelanggan pada nasabah Bank Mandiri Cabang Alam Sutera Tangerang berbentuk jawaban kuesioner yang disebarkan.

\section{Data Sekunder}

Data sekunder yang digunakan oleh peneliti yaitu buku-buku mengenai teori kualitas pelayanan, kepercayaan, kepuasan pelanggan dan didukung oleh data pelanggan, dan data empiris yang bersumber pada objek penelitian yaitu Bank Mandiri Cabang Alam Sutera Tangerang.

\section{Sumber Data}

Sumber data penelitian yang digunakan peneliti adalah penelitian kuantitatif, yakni dalam menganalisa data yang menggunakan angka-angka rumus atau model matematis berdasarkan tujuan penelitian yang ditetapkan. Pendekatan yang dipakai adalah pendekatan eksplanatory research yakni dengan menggunakan pendekatan penjelasan yang berusaha untuk menguji dua hipotesis yang menyatakan hubungan sebab akibat antara dua variabel atau lebih.

\section{Data Internal}

Data internal adalah data yang menggambarkan situasi dan kondisi pada suatu organisasi secara internal. Dimana data yang digunakan oleh peneliti mencakup data pelanggan, promosi, jumlah pertumbuhan pasar modern dan data lainnya yang mendukung sebagai data empirik dalam penelitian.

\section{Data Eksternal}

Data eksternal adalah data yang menggambarkan situasi serta kondisi yang ada diluar organisasi. Data eksternal mencakup pada kuesioner yang disebarkan kepada responden yang dianggap mewakili pendapat dari populasi yang ada.

\section{Teknik Pengumpulan Data}

Teknik pengumpulan data dalam penelitian ini merupakan langkah penting untuk memperoleh data-data atau informasi secara sistematis dan terarah yang sesuai untuk digunakan peneliti dalam penelitian ini. Adapun teknik pengumpulan yang peneliti lakukan adalah dengan melakukan pengumpulan data dari penelitian lapangan (Field Research), dengan menggunakan beberapa teknik yaitu : 
1. Observasi, dalam peneletian ini peneliti melakukan dengan cara pengamatan langsung pada objek yang diteliti sehingga diperoleh gambaran yang jelas mengenai informasi yang ada terkait pengaruh kualitas pelayanan dan kepercayaan terhadap kepuasan pelanggan (nasabah) Bank Mandiri Alam Sutera Tangerang.

2. Wawancara, dalam penelitian ini peneliti juga menggunakan teknik pengumpulan data dengan cara melakukan tanya jawab dengan pihak-pihak terkait guna mendapatkan data dan keterangan yang menunjang analisis dalam penelitian.

3. Kuesioner, dalam penelitian ini peneliti melakukan teknik pengumpulan data dengan cara memberikan daftar pertanyaan kepada responden yang dijadikan sebagai sampel penelitian. Kuesioner yang dibagikan berupa daftar pertanyaan mengenai pengaruh kualitas pelayanan dan kepercayaan terhadap kepuasan pelanggan (nasabah) Bank Mandiri Alam Sutera Tangerang.

\section{Teknik Skala}

Dalam penelitian ini menggunakan skala likert, Menurut Sugiyono (2012:93) skala likert digunakan untuk mengukur sikap, pendapat dan persepsi seseorang atau sekelompok orang tentang fenomena sosial. Variabel yang akan diukur dijabarkan menjadi indikator variabel. Kemudian indikator tersebut dijadikan sebagai titik tolak untuk menyusun itemitem instrumen yang dapat berupa pernyataan atau pertanyaan. Jawaban setiap item instrumen yang menggunakan skala likert mempunyai gradasi dari sangat positif sampai sangat negatif.

Tabel 4. Teknik Skala

\begin{tabular}{cccc}
\hline Kualitas Pelayanan & Kepercayaan & Kepuasan Nasabah & Bobot Skors \\
Sangat Setuju & Sangat Setuju & Sangat Puas & 5 \\
Setuju & Setuju & Puas & 4 \\
Cukup Setuju & Cukup Setuju & Cukup Puas & 3 \\
Tidak Setuju & Tidak Setuju & Tidak Puas & 2 \\
Sangat Tidak Setuju & Sangat Tidak Setuju & Sangat Tidak Puas & 1 \\
\hline
\end{tabular}

Sumber: Sugiyono (2015:93)

\section{HASIL ANALISIS DAN PEMBAHASAN}

\section{Karateristik Responden}

Data mengenai identitas pelanggan bank mandiri cabang alam sutera tangerang menjadi responden dalam penelitian ini, dimaksudkan untuk mengetahui data-data yang berkaitan erat dengan responden (objek) yang diteliti. Data-data tersebut kemudian dapat digunakan sebagai arahan dalam menganalisis data berikutnya. Data-data mengenai identitas responden yang penulis sajikan dalam penelitian ini meliputi data tentang jenis kelamin, usia, pekerjaan, penghasilan. 


\section{Identitas Responden Berdasarkan Usia}

Pengumpulan data melalui kuesioner mengenai karakteristik responden berdasarkan Usia disajikan pada Tabel 5. berikut ini :

Tabel 5. Profil Berdasarkan Usia

\begin{tabular}{cccc}
\hline No & Usia & Jumlah & Presentase \\
\hline 1 & $18-25$ tahun & 176 & $54,7 \%$ \\
2 & $26-50$ tahun & 146 & $45,3 \%$ \\
3 & $>50$ tahun & 0 & $0 \%$ \\
\hline & Jumlah & 322 & $100 \%$
\end{tabular}

Sumber : Hasil Pengelohan Data, 2020.

Berdasarkan pada Tabel 4.1 menunjukan bahwa sebagian besar responden di usia 18-25 Tahun sebesar 54,7\%.

\section{Identitas Responden Berdasarkan Pekerjaan}

Pengumpulan data melalui kuesioner mengenai karateristik responden berdasarkan Pekerjaan disajikan pada Tabel 6. berikut ini :

Tabel 6. Profil Berdasarkan Pekerjaan

\begin{tabular}{cccc}
\hline No & Pekerjaan & Jumlah & Presentase \\
\hline 1 & Pelajar/Mahasiswa & 57 & $17,7 \%$ \\
2 & Pegawai Swasta & 38 & $11,8 \%$ \\
3 & Wirausaha & 172 & $53,4 \%$ \\
4 & Lainnya & 55 & $17,1 \%$ \\
\hline & Jumlah & 322 & $100 \%$
\end{tabular}

Sumber : Hasil Pengolahan Data, 2020.

Berdasarkan pada Tabel 6. menunjukan bahwa sebagian besar berdasarkan pekerjaan frekuensi tertinggi terletak pada responden wirausaha dengan jumlah 172 sebesar 53,4\% responden dan sisanya didominasi pelajar / mahasiswa, pegawai, lainnya.

\section{Uji Validitas}

Uji validitas menurut sugiyono (2011:122) adalah untuk mengetahui tingkat kevalidan dari instrumen kuesioner yang digunakan dalam pengumpulan data. Padapenelitan ini dilakukan dengan menggunakan alat SPSS 22 untuk mengetahui analisis uji validitas apakah pernyataan pada kuesioner layak untuk diteliti :

Tabel 7. Hasil Uji Validitas

\begin{tabular}{lllll}
\hline Variabel & Item & $\mathbf{R}_{\text {hitung }}$ & $\mathbf{R}_{\text {kritis }}$ & Keterangan \\
\hline $\mathrm{X} 1.1$ & 0,613 & 0,300 & Valid \\
$\mathrm{X} 1.2$ & 0,713 & 0,300 & Valid \\
$\mathrm{X} 1.3$ & 0,771 & 0,300 & Valid \\
$\mathrm{X} 1.4$ & 0,754 & 0,300 & Valid \\
$\mathrm{X} 1.5$ & 0,755 & 0,300 & Valid \\
\hline
\end{tabular}




\begin{tabular}{|c|c|c|c|c|}
\hline Variabel & Item & $\mathbf{R}_{\text {hitung }}$ & $\mathbf{R}_{\text {kritis }}$ & Keterangan \\
\hline \multirow{10}{*}{ Kualitas Pelayanan } & X1.6 & 0,810 & 0,300 & Valid \\
\hline & $\mathrm{X} 1.7$ & 0,779 & 0,300 & Valid \\
\hline & $\mathrm{X} 1.8$ & 0,758 & 0,300 & Valid \\
\hline & X1.9 & 0,749 & 0,300 & Valid \\
\hline & $\mathrm{X} 1.10$ & 0,774 & 0,300 & Valid \\
\hline & $\mathrm{X} 1.11$ & 0,632 & 0,300 & Valid \\
\hline & $\mathrm{X} 1.12$ & 0,635 & 0,300 & Valid \\
\hline & $\mathrm{X} 1.13$ & 0,637 & 0,300 & Valid \\
\hline & $\mathrm{X} 1.14$ & 0,721 & 0,300 & Valid \\
\hline & $\mathrm{X} 1.15$ & 0,695 & 0,300 & Valid \\
\hline \multirow{9}{*}{ Kepercayaan } & $\mathrm{X} 2.1$ & 0,737 & 0,300 & Valid \\
\hline & $\mathrm{X} 2.2$ & 0,791 & 0,300 & Valid \\
\hline & $\mathrm{X} 2.3$ & 0,792 & 0,300 & Valid \\
\hline & $\mathrm{X} 2.4$ & 0,750 & 0,300 & Valid \\
\hline & $\mathrm{X} 2.5$ & 0,850 & 0,300 & Valid \\
\hline & $\mathrm{X} 2.6$ & 0,806 & 0,300 & Valid \\
\hline & $\mathrm{X} 2.7$ & 0,802 & 0,300 & Valid \\
\hline & $\mathrm{X} 2.8$ & 0,794 & 0,300 & Valid \\
\hline & X2.9 & 0,769 & 0,300 & Valid \\
\hline \multirow{14}{*}{ Kepuasan Nasabah } & Y1 & 0,730 & 0,300 & Valid \\
\hline & Y2 & 0,760 & 0,300 & Valid \\
\hline & Y3 & 0,761 & 0,300 & Valid \\
\hline & Y4 & 0,757 & 0,300 & Valid \\
\hline & Y5 & 0,808 & 0,300 & Valid \\
\hline & Y6 & 0,767 & 0,300 & Valid \\
\hline & Y7 & 0,779 & 0,300 & Valid \\
\hline & Y8 & 0,761 & 0,300 & Valid \\
\hline & Y9 & 0,772 & 0,300 & Valid \\
\hline & Y10 & 0,643 & 0,300 & Valid \\
\hline & Y11 & 0,638 & 0,300 & Valid \\
\hline & Y.12 & 0,687 & 0,300 & Valid \\
\hline & Y.13 & 0,736 & 0,300 & Valid \\
\hline & Y.14 & 0,765 & 0,300 & Valid \\
\hline
\end{tabular}

Sumber : data diolah 2020.

Berdasarkan pada tabel 7. dapat dilihat bahwa uji validitas yang dilakukan terhadap 322 responden menghasilkan 39 pernyataan yang dinyatakan valid. Hal ini dapat disimpulkan bahwa dengan melihat setiap variabel yang memiliki nilai $\mathrm{R}_{\text {hitung }}$ lebih besar dibandingkan $\mathrm{R}_{\text {Kritis, }}$, hal ini mengindikasikan bahwa seluruh pernyataan yang dibuat dinilai layak dan dapat digunakan untuk keperluan penelitian. 


\section{Uji Reliabilitas}

Uji reabililtas menurut Sugiyono (2011:354) dilakukan untuk menentukan seberapa jauh hasil pengukuran tetap konsisten ketika mengukur dua kali atau lebih terhadap gejala yang sama menggunakan alat ukur yang sama.

Tabel 8. Hasil Uji Reliabilitas

\begin{tabular}{lccl}
\hline Variabel & $\mathbf{R}_{\text {Kritis }}$ & $\mathbf{R}_{\text {hitung }}$ & Keterangan \\
\hline Kualitas Layanan & 0,600 & 0,933 & Reliabel \\
Suasana Restoran & 0,600 & 0,923 & Reliabel \\
Kepuasan Pelanggan & 0,600 & 0,935 & Reliabel
\end{tabular}

Sumber : data diolah 2020.

Berdasarkan tabel 8. dapat dilihat bahwa uji reabilitas yang dilakukan terhadap 322 responden menunjukkan bahwa semua variabel dinyatakan reliabel. Hal ini dapat disimpulkan bahwa dengan melihat setiap variabel memiliki nilai alpha croncbach lebih dari 0,600 , artinya seluruh pernyataan yang dibuat dinilai layak dan dapat digunakan untuk keperluan penelitian.

\section{Pembahasan}

Tabel 9. Uji Parsial

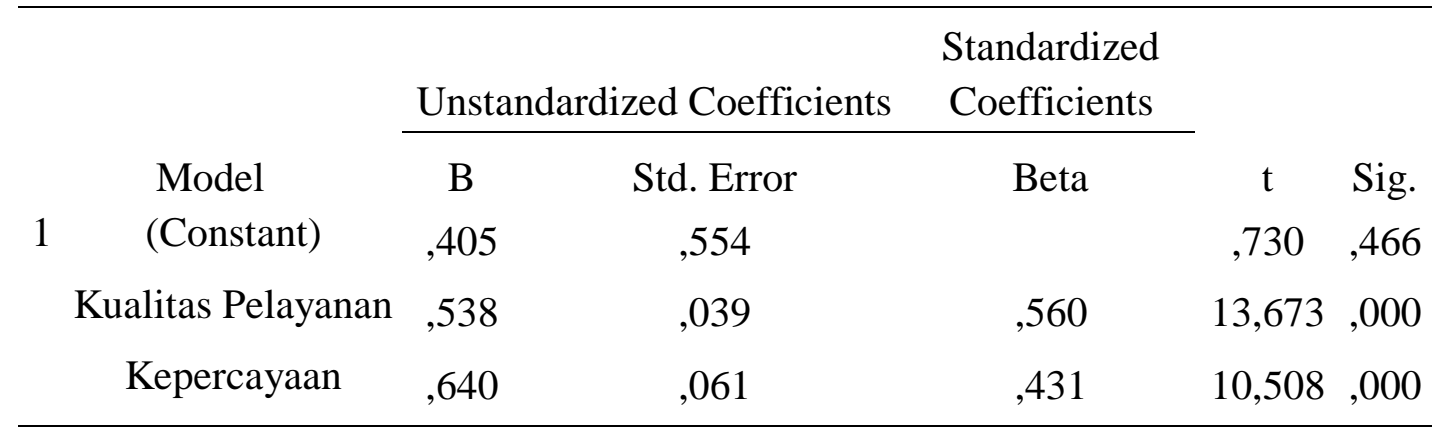

a. Dependent Variable: Kepuasan Nasabah

Sumber: Hasil Pengolahan Data,2020

Berdasarkan tabel 9. dapat disimpulkan bahwa nilai $t$ hitung variabel Kualitas Pelayanan adalah 13,673. Kemudiannilai $\mathrm{t}$ hitung selanjutnya dibandingkan $\mathrm{t}$ tabel dengan tingkat signifikan 5\%, $\mathrm{df}=\mathrm{n}-2=322-2=320$ diperoleh $\mathrm{t}$ tabel $=1,649$. Dengan demikian diketahui $\mathrm{t}$ hitung $(13,673)>\mathrm{t}$ tabel $(1,649)$, maka dapat dinyatakan bahwa $\mathrm{H}_{0}$ ditolak maka $\mathrm{H}_{1}$ diterima, artinya terdapat pengaruh yang signifikan antara Kualitas Pelayanan terhadap Kepuasan Nasabah pada bank mandiri cabang alam sutera tangerang. Hasil penelitian sesuai dengan penelitian terdahulu yang dilakukan oleh Lee Hyung Seok. 2013,Madona, F. (2017), Mustaqim, M. (2016), Dewi, A., dan Sri Padmantyo, M. B. A. (2017), danPutri, N. J. (2016) yang berpendapat bahwa kualitas pelayanan berpengaruh positif dan signifikan terhadap kepuasan pelanggan. 
Pada tabel 9. menunjukkan nilai $t_{\text {hitung }}$ variabel Kepercayaan adalah 10,508. Kemudian Nilai $\mathrm{t}_{\text {hitung }}$ selanjutnya dibandungkan $\mathrm{t}_{\text {tabel }}$ dengan tingkat signifikan $5 \%, \mathrm{df}=\mathrm{n}-2=322$ $2=320$ diperoleh $t_{\text {tabel }}=1,649$. Dengan demikian diketahui $t_{\text {hitung }}(10,508)>t_{\text {tabel }}(1,649)$, maka dapat dinyatakan bahwa $\mathrm{H}_{0}$ ditolak maka $\mathrm{H}_{1}$ diterima, artinya terdapat pengaruh yang signifikan antara Kepercayaan terhadap Kepuasan Nasabah pada bank mandiri cabang alam sutera tangerang. Hasil penelitian sesuai dengan penelitian terdahulu yang dilakukan oleh Guspul, A. (2014), Akfian Yuda Adhi et.al (2013) danErviana, O. (2013) yang menyatakan bahwa terdapat pengaruh yang signifikan antara Kepercayaan terhadap Kepuasan.

Tabel 10. Uji Simultan

\begin{tabular}{ccccccc}
\hline \multicolumn{1}{c}{ Sum of } & & & & \\
& Model & Squares & df & Mean Square & F & Sig. \\
\hline 1 & Regression & 27193,853 & 2 & 13596,927 & 4530,643 &, $000^{\mathrm{b}}$ \\
& Residual & 957,352 & 319 & 3,001 & & \\
& Total & 28151,205 & 321 & & & \\
\hline
\end{tabular}

Sumber: Hasil Pengolahan Data,2020

Berdasarkan tabel 9. hasil $\mathrm{F}_{\text {hitung }}$ menunjukan nilai $\mathrm{F}_{\text {hitung }}=4530,643$ dengan tingkat signifikasi 0,000, sedangkan nilai $F_{\text {tabel }}=3,031$. Nilai $F_{\text {hitung }}>F_{\text {tabel }}(4530,643>3,031)$ dan tingkat signifikansi $(0,000<0,050)$ dengan hipotesa $\mathrm{H}_{0}$ ditolak dan $\mathrm{H}_{1}$ diterima, sehingga dapat disimpulkan bahwa terdapat pengaruh secara simultanantara Kualitas Pelayanan dan Kepercayaan terhadap Kepuasan Nasabah pada bank mandiri cabang alam sutera tangerang. Hasil penelitian sesuai dengan penelitian terdahulu yang dilakukan oleh Guspul, A. (2014) dan Akfian Yuda Adhi, et.al (2012), menyatakan bahwa kualitas pelayanan dan kepercayaan berpengaruh positif dan signifikan terhadap kepuasan pelanggan.

\section{PENUTUP}

\section{Simpulan}

Dari hasil penelitian dan pembahasan yang telah dijelaskan pada bab sebelumnya, maka dapat disimpulkan sebagai berikut:

1. Hasil pengujian hipotesis menggunakan uji-t menunjukan bahwa terdapat pengaruh yang signifikanKualitas pelayanan terhadap Kepuasan nasabah bank mandiri cabang alam sutera tangerang.

2. Hasil pengujian hipotesis uji-t menunjukkan bahwa terdapat pengaruh yang signifikan antara kepercayaan terhadap kepuasan nasabah.

3. Hasil pengujian hipotesis uji-f menunjukkan bahwaantara Kualitas Pelayanan dan Kepercayaan terhadap Kepuasan Nasabah pada bank mandiri cabang alam sutera tangerang. 


\section{Saran}

1. Mengacu pada variabel kualitas pelayanan berdasarkan indikator terendah yaitu kecepatan karyawan dalam melayani nasabah hal ini ini menunjukan bahwa karyawan perlu di perbaiki dalam kecepatan untuk melayani nasabah tiap harinya.

2. Mengacu pada variabel kepercayaan berdasarkan indicator terendah yaitu karyawan terampil dalam memberikan informasi kepada nasabah, hal ini menunjukan bahwa karyawan bank mandiri cabang alam sutera tangerang perlunya menambah wawasan prosedur pelayanan yang untuk menanggapi nasabah dengan cepat, mudah dan nyaman.

3. Mengacu pada variabel kepuasan nasabah berdasarkan indikator terendah yaitu pegawai siap dan membantu di tempat ketika mereka diperlukan, hal ini menunjukan bahwa karyawan bank mandiri cabang alam sutera tangerang menerapkan sistem tanggap dalam membantu para nasabah di tempat ketika mereka memerlukan para karyawan.

\section{Rekomendasi Penelitian Selanjutnya}

1. Pada variabel $X$ dapat ditambahkan agar hasil penelitiannya lebih menggambarkan mengenai objek yang akan di teliti.

2. Populasi penelitian diperluas lagi serta penambahan pada sample agar hasil penelitian lebih memuaskan. 


\section{DAFTAR PUSTAKA}

Akfian Yuda Adhi Dan Nina Ernawati. 2012. Pengaruh Dimensi Kualitas Pelayanan Dan Kepercayaan Konsumen Terhadap Kepuasan Konsumen Hotel Candi Indah Semarang. Jurnal Mahasiswa Qman, Volume I, No. 3, Mei 2012, Halaman 44-56.

Dewi, A., \& Sri Padmantyo, M. B. A. (2017). Pengaruh Kualitas Pelayanan Kepuasan Pelanggan Terhadap Loyalitas Nasabah (Studi Kasus Di Bank Bri Surakarta) (Doctoral Dissertation, Universitas Muhammadiyah Surakarta).

Erviana, O. (2013). Pengaruh Kualitas Pelayanan Dan Kepercayaan Terhadap Kepuasan Pasien Rawat Inap Di Rsud Dr. Soewondo Kendal. Jurnal Manajemen. Fakultas Ekonomi, Universitas Negeri Semarang.

Guspul, A. (2014). Pengaruh Kualitas Pelayanan Dan Kepercayaan Terhadap Kepuasan Nasabah. Jurnal Penelitian dan Pengabdian kepada Masyarakat UNSIQ, 1(1), 40-54.

Lee Hyung Seok. 2013. Major Moderators Influencing the Relationships of Service Quality,Customer Satisfaction and Customer Loyalty. Business Journal. 9(2) ,pp.111 .

Madona, F. (2017). Pengaruh Kualitas Pelayanan Terhadap Kepuasan Nasabah Pada Pt. Bank Syariah Mandiri Kantor Cabang 16 Ilir Palembang.[Skripsi] (Doctoral Dissertation, Uin Raden Fatah Palembang).

Mustaqim, M. (2016). Kualitas Pelayanan Terhadap Kepuasan Nasabah Bank Muamalat Cabang Palangka Raya (Doctoral Dissertation, Iain Palangka Raya).

Mosahab, Rahim., PhD Candidate., Osman Mahamad., dan T. Ramayah, Associate. 2010. Service Quality, Customer Satisfaction and Loyalty: A Test of Mediation. International Business Research, 3 (4), pp.72-80.

Putri, N. J. (2016). Pengaruh Kualitas Pelayanan Produk Tabungan Berencana Terhadap Kepuasan Nasabah Bank Syariahmandiricabangpurwokerto) (Doctoral Dissertation, Iain Purwokerto).

Sugiyono. 2011. Metode Penelitian Kuantitatif Kualitatif Dan R \& D. Cetakan Lima. Bandung. Alfabeta.

Sugiyono. 2013. Metode Penelitian Manajemen. Cetakan Pertama. Bandung. Alfabeta.

Tjiptono, Fandy. 2009. Strategi Pemasaran. Edisi Kedua. Cetakan Ketujuh. Yogyakarta. Andi.

Tjiptono, Fandy. 2014. Pemasaran Jasa. Edisi Pertama, Cetakan ke Sepuluh. Yogyakarta. Andi.

Yulianto, Tri. 2015. Pengaruh Kualitas Pelayanan Atm Dan Kepercayaan Terhadap Kepuasan Nasabah Pada Nasabah Bank Bri Fakultas Ekonomi Dan Bisnis Universitas Muhammadiyah Surakarta. Surakarta. 
